\title{
LA IMPORTANCIA DEL ANÁLISIS ESTRATIGRÁFICO DE LAS CONSTRUCCIONES HISTÓRICAS EN EL DEBATE SOBRE LA RESTAURACIÓN MONUMENTAL
}

\author{
(THE IMPORTANCE OF STRATIGRAPHIC ANALYSIS OF HISTORICAL CONSTRUCTIONS IN THE \\ DISCUSSION ON THE RESTORATION OF MONUMENTS)
}

Pablo Latorre González - Moro, Arquitecto

Estudio de Arquitectura Latorre y Cámara-Madrid

Luis Caballero Zoreda, Dr. Arqueólogo

Centro de Estudios Históricos - CSIC - Madrid

Fecha de recepción: 13-II-95

105-13

ESPAÑA

\begin{abstract}
RESUMEN
La doble valoración que del edificio histórico puede hacerse como arquitectura y como documento histórico, la necesidad simultánea de conservarlo con toda su carga documental y la exigencia de intervenir sobre él, transformándolo para cumplir este cometido, han marcado las diferentes teorias de la restauración. Los defensores de la conservación a ultranza de los valores documentales no han sido capaces de definir, mas allá de los aspectos pintorescos y literarios, estos valores. En este contexto, la aparición de la metodología para el análisis estratigráfico de las construcciones históricas, ha permitido la definición y el análisis científico y sistemático de los valores documentales de las arquitecturas del pasado. Este reconocimiento permitirá decidir de forma razonada y justificada, a la hora de acometer la restauración, su conservación o eliminación.
\end{abstract}

\begin{abstract}
SUMMARY
The different restoration theories have been marked by the double valuation of a historical building as architecture and as historical document, i.e. the simultaneous necessity to preserve it with all its documentary contents on the one hand, and the demand for treating it in order to direct it towards reaching this goal on the other. The defendors of preservation of documentary values at all costs have not been able to define these values beyond mere picturesque and literary aspects. Within this context, the appearance of the methodology for stratigraphic analysis of historical buildings has allowed the definition, and scientific and systematic analysis of the documentary values of the architectures of the past. This examination will allow to decide, in a reasoned and justified way, their elimination or preservation, when we are to undertake the restoration.
\end{abstract}

El monumento nazari ha ido viviendo y transformándose al correr del tiempo; cada año, cada hora fue dejando enél su huella. Hasta las mismas entrañas del edificio fueron removidas cienveces. Al examinar cualquier muro se ve como en él se combinan las fábricas más heterogéneas; como, sustentando las primitivas de tierra rojiza, hay en muchos lugares porciones más modernas; como se han sucedido recalzos y remiendos Cada uno es un muestrario de las más diversas fábricas construidas en todas las épocas, desde el siglo XIV hasta nuestros días. L. Torres Balbás, Granada, 1924. 
1.-El monumento y su doble valoración como estructura arquitectónica y como documento histórico.

La restauración ${ }^{1}$ de la arquitectura histórica se ha movido entre dos polos irreconciliables determinados, primero, por ladualidad que existe entre la valoración del monumento como estructura arquitectónica y su valoración como documento histórico y, segundo, por la paradoja que se produce entre la necesidad de la estricta conservación de los restos heredados y la necesaria transformación de los mismos para cumplir este cometido.

La posibilidad de entender la arquitectura histórica desde estas ópticas diferentes ha sido la causante de las distintas polémicas, los criterios dispares, los enfrentamientos entre profesionales y, en definitiva, el germen de las diferentes teorías de restauración. Los partidarios de la intervención, entienden el edifício como un problema de construcción, de mecánica, de estática, de espacio, de luz, de tipología, de estilo, de contenedor de actividades humanas, etc., en definitiva, como un problema de arquitectura. Los partidarios de la conservación valoran el edificio como un documento históricoy exigen la "autenticidad" del material que lo conforma, pues saben que cualquier intervención puede hacer desaparecer algún elemento primordial para la comprensión de la historia del mismo.

Esta polémica entre especialistas se ha centrado, a nivel teórico, en la definición de los "valores" de la arquitectura histórica que es necesario transmitir y, en consecuencia, conservar o restaurar. Por un lado se encuentran los que prefieren la restauración de los valores arquitectónicos (forma, construcción, función), que consideran originales o simplemente más significativos; aunque para conseguir este objetivo tengan que renunciar a la autenticidad del material y de toda su carga simbólica e histórica-demoliendo para ello todas las adiciones que lo desfiguran y reconstruyendo las partes perdidas-. Por el otro, los que prefieren conservar la forma del edificio transformado, tal y como la hemos recibido por "adulterada" que esté la forma primitiva, como testimonio de los acontecimientos históricos que se han desarrollado en su interior y reflejo de las distintas culturas que las han producido.

Aloïs Riegl, en su libro de 1903, El culto moderno a los monumentos, ya establece la posibilidad de realizar esta doble valoración de los monumentos, diferenciando entre su valor de antigüedad y su valor histórico.

Según el valor de antigüedad, lo que se valora de los monumentos es la transformación del edificio primero por acción de la naturaleza en el tiempo "...lo que complace
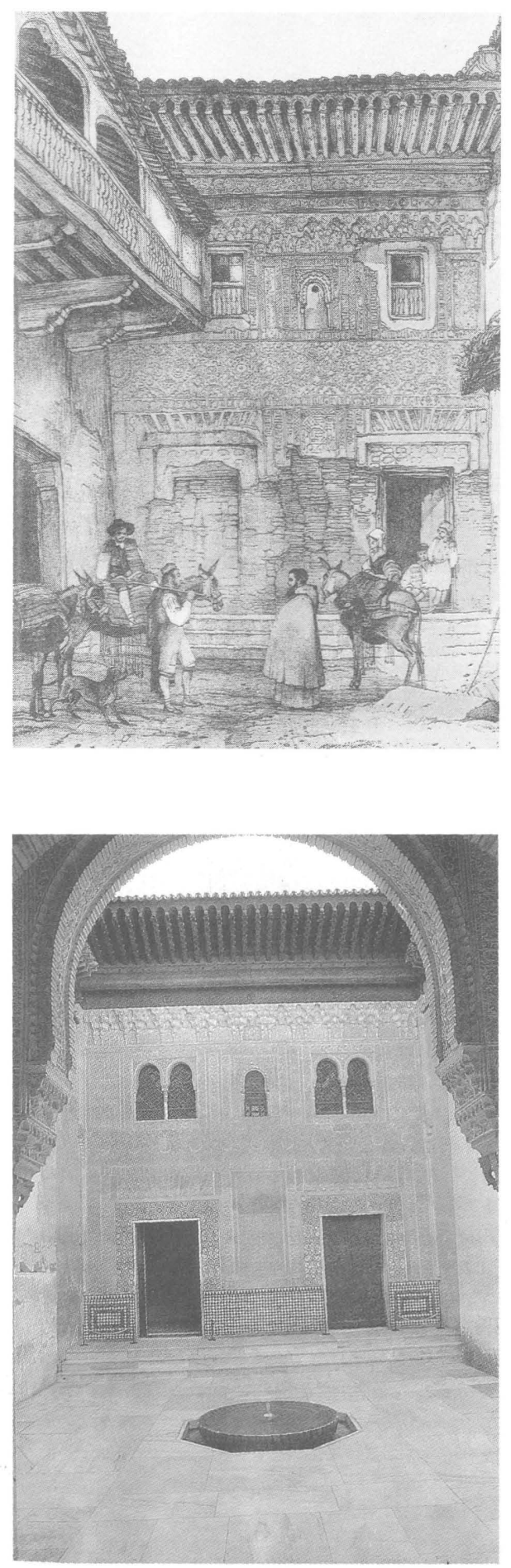

Fig.1.- Cada muro es un muestrario de todas las épocas, desde el siglo XIV hasta nuestros dias. Fachada del palacio de Comares de la Alhambra de Granada, según Lewis, 1833.

Fig.2.- Los que prefieren la restauración de los valores arquitectónicos que consideran originales o más representativos. Fachada del palacio de Comares en la actualidad.

\footnotetext{
${ }^{1}$ La palabra restauración tiene un doble significado que puede conducir al equívoco. De acuerdo con el diccionario de la Real Academia, se entiende por restauración las actuaciones -conservar, consolidar, reponer, restablecer, reconstruir, rehabilitar, restaurar-tendentes a "reparar" un edificio del deterioro que ha sufrido. Pero la palabra restauración se ha utilizado también para designar las actuaciones "violletianas" dirigidas a "restaurar" el edificio a un estado ideal que pudo nunca haber tenido. Para evitar este doble significado, se ha sustituido la palabra restauración, en su significado más amplio, por el de intervención, reservando la palabra restaurar para designar un tipo concreto de intervención. En el texto, seguimos utilizando el doble significado de la palabra restauración que se entiende por el contexto de la frase en la que se sitúa.
} 
al hombre contemporáneo es más bien el ciclo natural de creación y destrucción en toda su pureza, así como percibirlo con toda claridad...; pero aclara, que, para valorar la antigüedad de un monumento, es preciso que quede alguna huella clara de la forma original, pues .. un montón de piedrasya sólorepresenta un fragmento muerto, informe, de la madre naturaleza, sin huellas de creación viva...

Según el valor histórico de los monumentos no nos interesan las huellas de erosión, sino su génesis como obra humana. El valor histórico será tanto mayor, cuanto menor sea la alteración sufrida en su estado originario. La labor del historiador es rellenar de nuevo, con todos los medios auxiliares a su alcance, los vacíos que las influencias de la naturaleza han producido en la forma originaria con el transcurso del tiempo. Pero Riegl, advierte de los peligros que la subjetividad del autor puede imponer a una restauración: ...El valor histórico no ignora que todo cálculo humano y toda restauración están expuestas al valor subjetivo...

La valoración de antigüedad e histórica, establecidas por Riegl, encierran un concepto decimonónico de la historia, al entender la antigüedad del monumento como anticuaria -refiriéndose al estudio del objeto aislado y descontextualizado, valioso únicamente porque es muy viejo o antiguo- y su valor histórico únicamente desde su aspecto estético, formal y estilístico. Riegl cree que un montón de piedras "informe" no conserva huellas de la actividad humana, cuando es evidente que sí las conserva como nos dice la práctica diaria de la arqueología histórica, y advierte del peligro que la subjetividad del restaurador puede imprimir falsificando la forma originaria. Sin embargo, en esta valoración, ha estado el germen de las diferentes teorías de la restauración y todavía en la actualidad es repetida por los profesionales de la restauración para justificar su posición crítica frente al monumento.

En esta clasificación,se ha obviado referirse a personajes como Viollet o Ruskin para evitar caer en una simplificación del problema, e identificar a unos y a otros con la conservación y la restauración. El problema es mucho más complejo y rico que el que puede encerrar esta división y sigue estando en el fondo de toda la polémica sobre la restauración monumental. Ya dudaba Torres Balbás de esta clasificación entre las escuelas restauradoras y antirrestauradoras y calificaba de tópico el clasificar a los técnicos que dirigían las obras entre los partidarios de las restauraciones y a los teóricos (arqueólogos, literatos y artistas) en el campo contrario. Esta división simplista era inaceptable para Torres Balbás pues suponía reconocer que la teoría conservadora, con cuyos principios él se sentía identificado, era inaplicable en la práctica.

Fig.3.- La Torre de las damas de la Alhambra, restaurada según la teoría conservadora defendida por Torres Balbás (según Gallego Roca).

\section{2.-Elvalor arqueológico de las construcciones históricas.}

Sin querer convertir este artículo en una exposición sobre las teorías de la restauración, queremos fijar de nuevo la atención sobre la valoración que se imputa al monumento comodocumento. Parececlaro, desde una visión romántica y "ruskiniana" de la arquitectura, que los edificios antiguos $\mathrm{y}$, sobre todo, las ruinas reflejan en su aspecto el paso del tiempo, es decir, su historia.

Desde esta óptica más conservacionista de la intervención sobre los monumentos, se culpabiliza a las teorías restauradoras e intervencionistas de hacer desaparecer, con las obras de restauración, este "climax", dotando a los edificios históricos de un nuevo aspecto, mucho más frío, en el que este efecto evocador del paso del tiempo ha desaparecido

Esta idea del efecto devastador que la intervención de los arquitectos provoca en los edificios históricos, está intimamente ligado a ciertos sentimientos, como el que expresa Valle Inclán en su cuento La Cabeza del Dragón: Es un castillo de fantasía como lo saben soñar los niños. Tiene grandes muros cubiertos de hiedra, y todavía no ha sido restaurado por los arquitectos del rey. iAlabemos a Dios!

En esta reivindicación, ninguno de los autores conservacionistas es capaz de definir, más allá de los

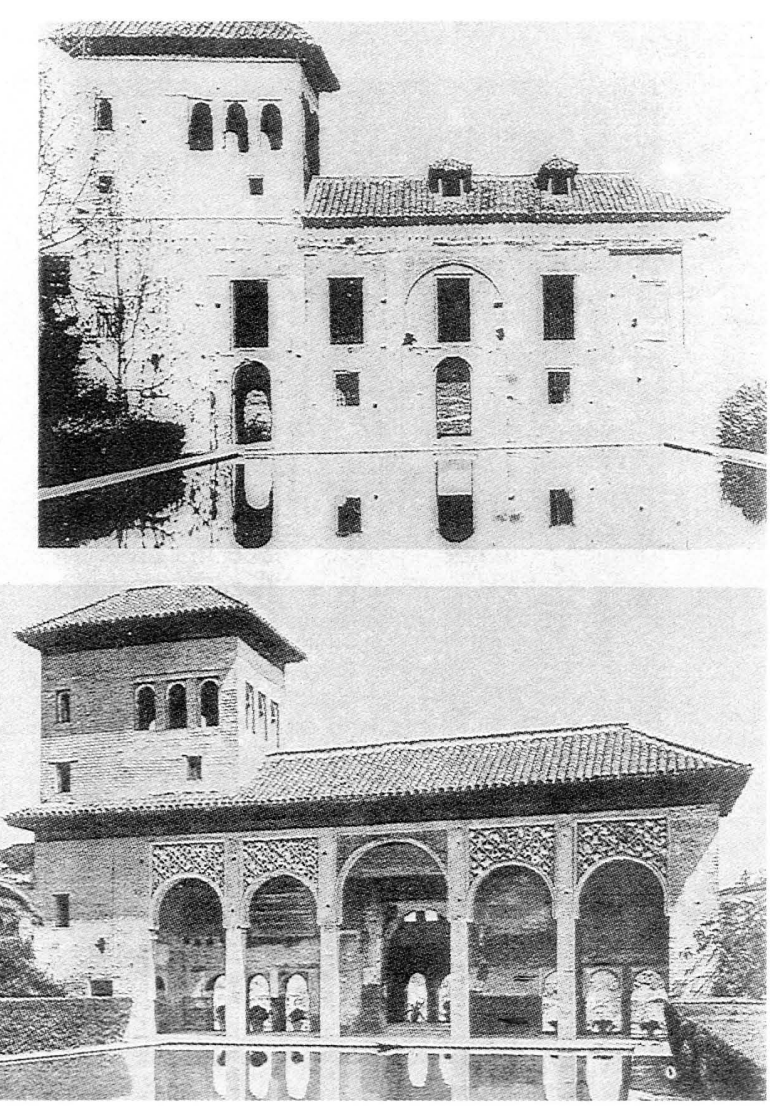


aspectos estéticos, literarios o pintorescos, en qué consiste esta pérdida del carácter evocador del paso del tiempo, llegando al contrasentido, eso sí, de un alto valor poético, de afirmar el derecho a morir de los edificios.

De todos son conocidas las afirmaciones y declaraciones de Ruskin en su libro Las siete lámparas de la arquitectura, al final del capítulo VI, después de recordarnos todos los cuidados que deberemos guardar para con el viejo edificio y ofrecernos un catálogo de soluciones para conseguir este fin, proclama la muerte del edificio: ...Su última hora sonará finalmente; pero que suene abierta y francamente, y que ninguna institución deshonrosa venga a privarla de los honores fúnebres del recuerdo...

En contraposición, la actitud positiva y posibilista de las intervenciones restauradoras, manejaba criterios científicos, objetivos y valorables como son los constructivos y estructurales y ofrecían una solución, prolongando la vida del monumento. Estos autores exigían la recuperación de los valores arquitectónicos del edificio y tildaban de falta de cientificismoa aquellos que reclamaban valores literarios para la conservación de los monumentos y afirmaban la fealdad de las ruinas como algo incompleto, como una mutilación del objeto completo, queen verdad, sí representa la belleza.

En este punto del planteamiento debemos preguntarnos: ¿por qué un edificio histórico, no restaurado, refleja el paso del tiempo?; ¿qué relaciones existen entre sus elementos constructivos para que tal cosa suceda?

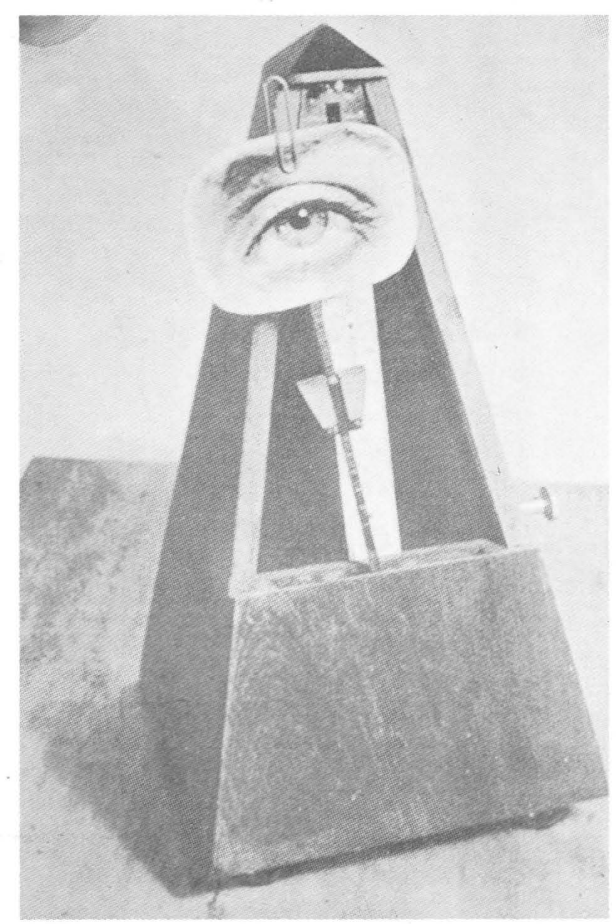

Fig.4.- ¿Enqué se refleja el paso del tiempo? "Objeto a destruir", Fotografía de Man Ray.
Torres Balbás reclamaba en sus escritos la conservación de los "valores arqueológicos" de los edificios, como respuesta a esta problemática : ...Aún tendremos seguramente que realizar muchas campañasen defensade los viejos edificios que se quieren restaurar radicalmente o completar, haciendo desaparecer su valor arqueológico, y, lo que es más grave, privándoles de la belleza y el factor pintoresco que el tiempo les ha ido prestando en una labor secular... En su artículo de 1918 en la revista Arquitectura, además de sus afirmaciones, recoge testimonios de diferentes autores -F. de Goya, A. France, J. Puig y Cadafalch y Anasagasti- que, con la misma idea por él defendida, tratan de valorar como algo muy positivo el efecto transformador y modelador que el tiempo impone a los edificios y las obras de arte, señalando que es éste, y nootro, el valor arqueológico de los edificios.

Siguiendo el razonamiento de Torres Balbás y de todos los autores que incluye en su artículo, deberíamos preguntarnos, ¿en qué consiste el valor arqueológico de un edificio?, ¿se puede estudiar, analizar, definir, determinar y, como consecuencia, individualizar y conservar?, ¿qué tiene de arqueológico un edificio y en consecuencia, qué paralelismo existe entre éste y un yacimiento arqueológico?

Todo este cúmulo de preguntas, ha quedado sin una respuesta concreta. Los autores conservacionistas no han sabido definir, más allá de las sensaciones, qué es lo que se debía conservar de la materia del edificio para no perder este valor. Para resolver este problema, se ha exigido la conservación a ultranza de todo cuanto ha llegado hasta

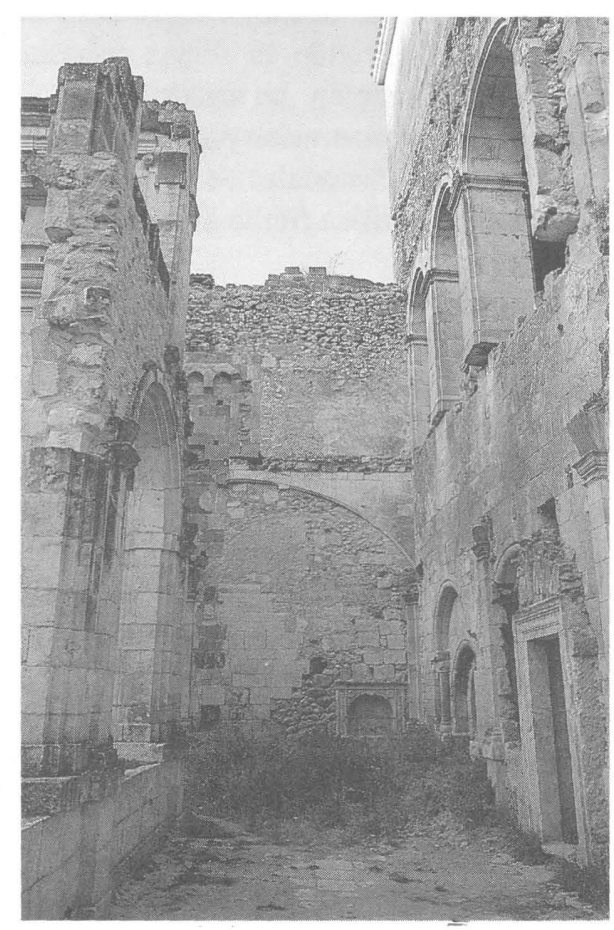

Fig.5. - ¿En qué consiste el valor arqueológico de un edificio? Monasterio de S. Pedro de Arlanza ( Burgos). 
nosotros, con el convencimiento de que su embalsamamiento era la única medida eficaz para conservar el documento histórico. Conservando todo, al intervenir lomenos posible, se estaba seguro de no perder nada y poder transmitir al futuro el edificio en toda su "autenticidad".

\section{3.- El edificio histórico y su estratificación constructiva.}

La materialización de un edificio responde formalmente, a los planteamientos estéticos o estilísticos de las personas que lo idearon y lo construyeron; tipológicamente, espacialmente, etc., a los problemas como contenedor de usos que pretendía resolver; constructivay estructuralmente, a la tecnología y los conocimientos de su momento; y, finalmente, responde a los condicionantes que el lugar de su construcción le impone. Forma, construcción, función y entorno determinan simultáneamente tanto la génesis de su arquitectura como la de las transformaciones a las que se verá sometido.

Guerras, abandonos, cambio de usuarios, ampliaciones por aumento de la comunidad que lo habita, catástrofes naturales, colapsos por problemas estructurales, la especulación urbana o simplemente el capricho de algún obispo, reina o valido, han modelado el edificio que ha llegado hasta nosotros, modificando su forma, su construcción, el modo en que se usa y el entorno en el que se asienta.
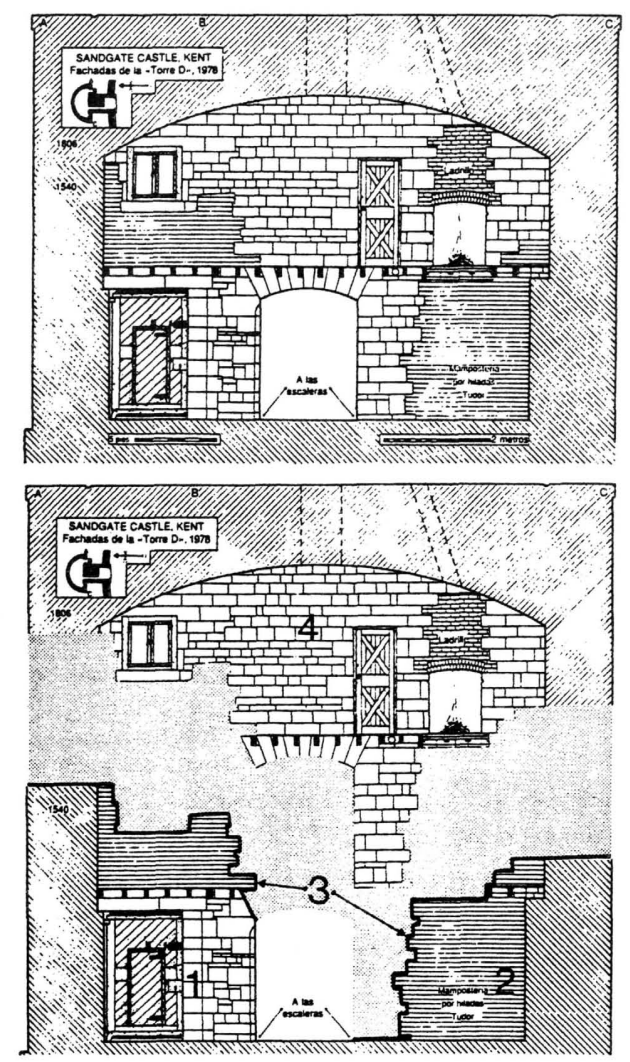

Fig.6.- Estratos verticales -1, 2 y 4-e interfaz -3-del Sandgate Castle de Kent, 1978 ( según Harris).
Este proceso es continuo en el tiempo y cualquier reforma originada por la modificación de uno de estos valores incidirá inmediatamente en los restantes. Por este motivo las partes que componen un edificio histórico forman un sistema complejo que no responde de un modo lineal a las transformaciones que sobre él se introduzcan.

Estas transformaciones se producen por una sucesión continua de acciones constructivas, bien sean por sustracción de material (demoliciones o colapso) o por adición del mismo (reconstrucción). Estas acciones constructivas tienen
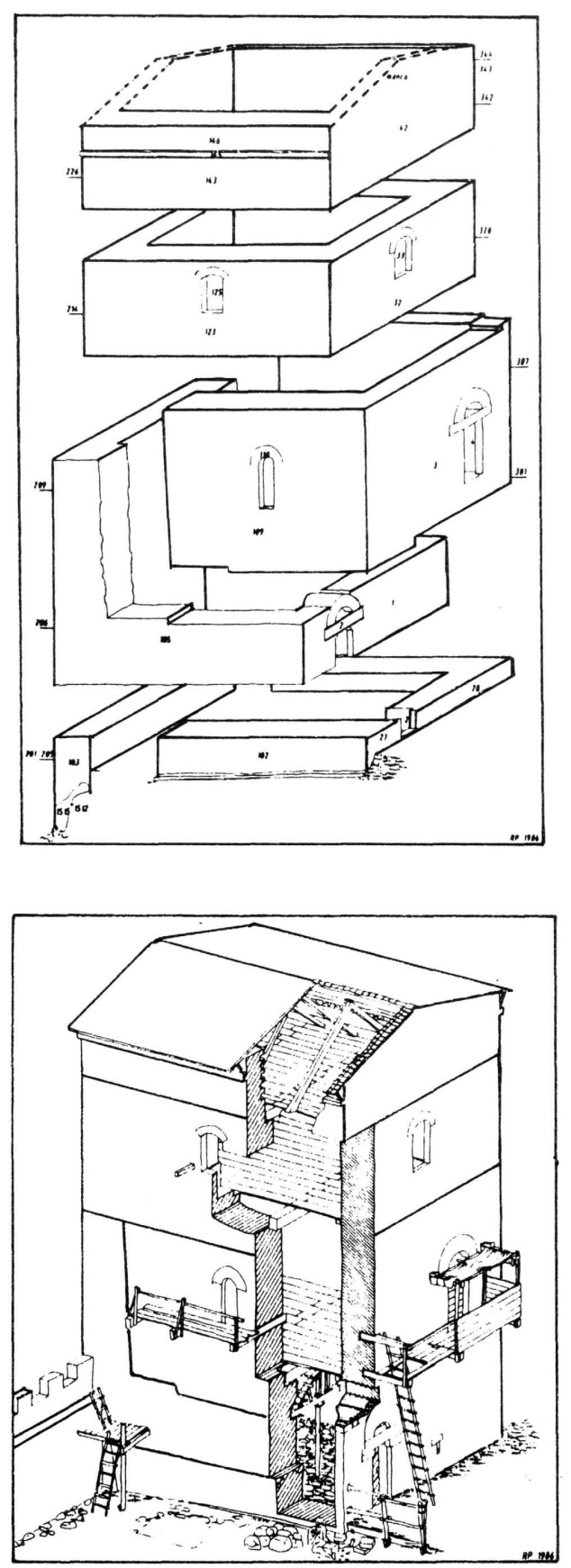

Fig.7.-Actividades constructivas, fases de obra yetapas y reconstrucción de la fase bajo medieval. Torre B de Montarrenti ( Siena), según Parenti, 1985 . 
que ejecutarse siguiendo el "orden" que impone la estática del edificio y las tradiciones artesanas de los oficios de la construcción, o bien se producen de forma accidental por causas naturales. El material que compone el edificio, siguiendo este proceso de sustracción (negativo) y adición (positivo), va superponiéndose y adosándose a la primera estructura construida, siguiendo unos principios básicamente similares a los de la estratificación geológica y arqueológica, aunque lógicamente existen diferencias de matiz, terminológicas, formales, instrumentales, etc.

La metodología que se presenta desde estas páginas para definir la estratificación de un edificio histórico, es una consecuencia de la utilizada para los análisis estratigráficos de las excavaciones arqueológicas de la ciudad de Londres, recogida y sistematizada por Harris en su libro de 1979 , Principios de estratigrafia arqueológica. Harris, apunta ya en su libro, la posibilidad que existe de aplicar el método de análisis por él expuesto a las edificios históricos. Sin embargo, la aplicación sistemática del "método Harris" al análisis de la arquitectura, ha sido desarrollada por la Cátedra de Arqueología Medieval de la Universidad de Siena. Dos profesores de este departamento, ambos arquitectos, R. Parenti y G.Brogiolo -que colaboran con sendos artículos en este número de la revista- han sido los que con la utilización y puesta en práctica del método han conseguido sistematizarlo y difundirlo.

\section{4.- Tiempo Histórico y fases constructivas.}

Una estructura arquitectónica antigua se convierte, por la "estratificación" del material constructivo, en un importante documento histórico. La aplicación de los principios de la estratificación (método Harris) al estudio de la génesis de un edificio, nos permite definir una secuencia que ordena las fases constructivas del mismo, determinando su relación temporal.

La clasificación temporal del material constructivo que compone un edificio se consigue primero reconociendo y aislando cada una de las acciones constructivas que lo componen y definiendo los materiales que la integran. El resultado de estas acciones constructivas o destructivas, producidas por causas naturales o artificiales, voluntarias o involuntarias, con aportación de material o sustracción del mismo, lo consideramos una unidad estratigráfica. Las unidades estratigráficas son una consecuencia de la acción constructiva, lo que provoca la existencia de unidades estratigráficas que no poseen valor material (interfaces), sino únicamente espacial y temporal, pues son la consecuencia de una interrupción constructiva o de una sustracción de material. Cada una de estas unidades será reconocible y se podrá diferenciar del resto porque ocupará una posición en el edificio distinta a las demás, pertenecerá a un momento concreto y tendrá una función determinada.

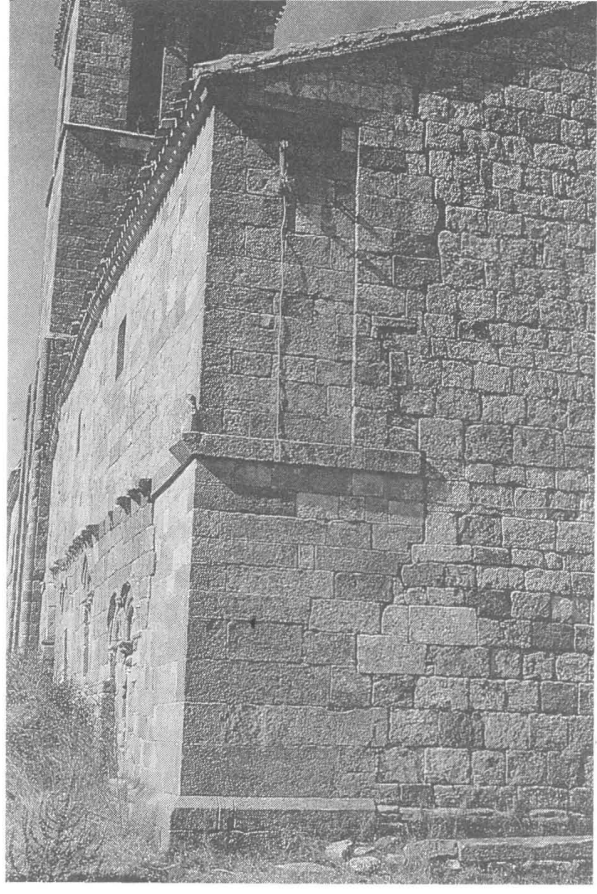

Fï.8. - Lara de los Infantes (Burgos).

Definidas las unidades estratigráficas que componen la construcción, se estudiarán las relaciones de anteroposterioridad (apoya, corta, se adosa, cubre, es cubierto por, etc.) que existen entre los materiales constructivos de las mismas. Finalmente se establecerá una representación en árbol, (diagrama estratigráfico periodizado), de todos los elementos que componen el edificio.

El diagrama estratigráfico nos permitirá identificar las unidades estratigráficas ejecutadas en el mismo momento y por tanto plantear las hipótesis de la "forma" del edificio en una etapa determinada, pero también nos permitirá estudiar el proceso diacrónico de construcción, crecimiento y transformación del edificio.

La riqueza de relaciones que se produce entre los materiales de un edificio es la que provocan la sensación y evocación del paso del tiempo a través del mismo, reivindicado por los autores conservacionistas. Estas relaciones son las que se pueden descubrir, analizar e individualizar con el método que se presenta desde estas páginas. Estas relaciones no son otra cosa que el objeto del estudio arqueológico y es por este motivo que este análisis sea metodológicamente arqueológico, aunque su aplicación exija un análisis exhaustivo y meticuloso de la evolución constructiva del edificio. Esta red de relaciones entre los elementos de un edificio que se comprende como un sistema no es otra cosa que la noción de "contexto" definida en arqueología.

El "contexto" es el conjunto de elementos que componen una unidad espacial, cronológica y social y por tanto constructiva, tal y como ha llegado hasta nosotros a través 


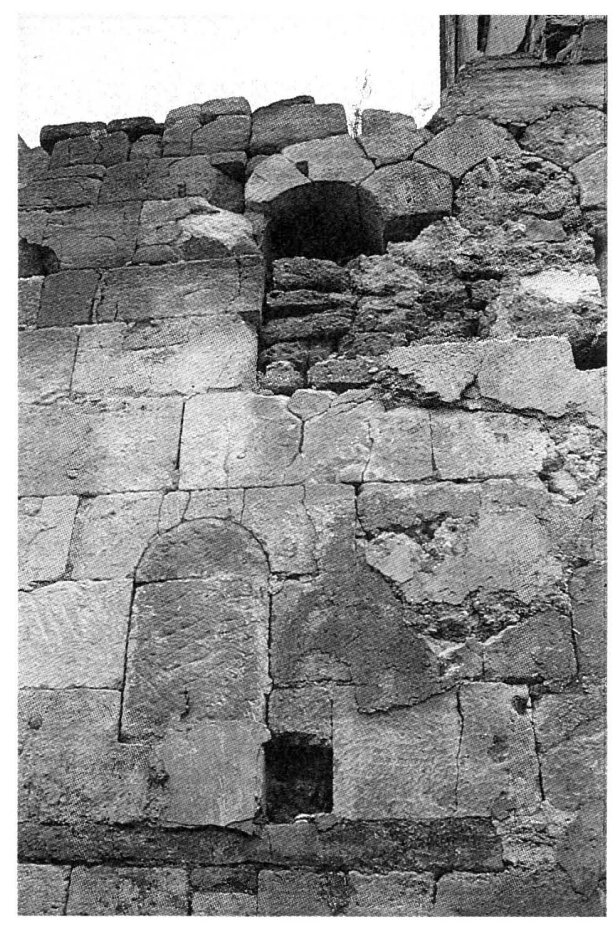

Fig. 9.- S. I Iicente del l'alle, Belorado (Burgos). Estratigrafia de distintas unidades constructivas, aparejos, ventanas, cierres, recubrimientos, ...

del tiempo y de tal modo que su unidad presenta unas características que la distinguen del resto y la hacen especialmente significante.

La pérdida de estas relaciones "contextuales" entre los elementos constructivos es la que provoca la ausencia del efecto evocador del paso del tiempo a la que nos hemos estado refiriendo y no la pérdida del material mismo como se ha pretendido. Pueden existir elementos del edificio que, poseyendo una gran importancia artística o una gran presencia formal en el mismo, tienen relaciones estratigráficas con sus elementos adyacentes muy pobres y a la inversa, elementos de una escasa importancia artística y formal que, sin embargo, poseen una gran riqueza en sus relaciones contextuales con los elementos colindantes, resultando clave su conservación para la comprensión histórica del mismo.

El conocimiento y documentación de la unidad contextual del edificio será imprescindible para su conocimiento histórico. Documentaday conocidala riqueza de relaciones que se producen entre los materiales de un edificio, se podrá acometer su restauración con un criterio objetivo y decidir su eliminación para favorecer la consolidación de otros aspectos del edificio o su conservación.

\section{5.- Edificio y yacimiento, una unidad histórica.}

El edificio comprendido como una realidad construida y estratificada se convierte en un importantísimo documento que, por su propia génesis, se encuentra íntimamente unido con el subsuelo sobre el que se encuentra, ya que ambos se generaron simultáneamente. Harris plantea que fue la actividad constructiva la que creó los yacimientos, a la vez que el urbanismo se iba transformando. Edificio y subsuelo arqueológico forman un solo yacimiento, con una historia común. El edificio y su yacimiento se han creado en un mismo proceso y son realidades que tienen entre sí profundas semejanzas.

Sin embargo, Arqueología y Arquitectura han convenido históricamente la separación del objeto de su trabajo mediante una superficie divisoria que se sitúa en el nivel del terreno. El arquitecto, dueño de las estructuras arquitectónicas, vela por su estabilidad y conservación. El arqueólogo se empeña en "desmontar" terrenos tratando de recuperar la historia a través de los restos de cultura material, susceptibles de ser analizados con metodología estratigráfica. Pero esta superficie divisoria es ilusoria; objeto y finalidad se confunden en ambos casos

Esta continuidad constructiva y documental entre las estructuras que existen en el subsuelo y las aéreas nos obliga a no separarlas en los estudios de los edificios. Existe un paralelismo histórico innegable en la creación de ambos, tanto desde el punto de vista espacial, constructivo y cronológico como desde el punto de vista social, pues ambos tuvieron un uso similar. El edificio histórico, se somete a las mismas leyes de evolución y formación que el yacimiento y por tanto debe comprenderse y analizarse del mismo modo

La problemática aludida queda perfectamente definida en el artículo que Caballero publicó en 1987, con el título El método arqueológico en la comprensión del edificio (sustrato y estructura): ... la conclusión es que la lectura del edificio y la lectura del sustrato arqueológico deben efectuarse a la vez y de modo que se consiga una lectura unitaria, considerando que las relaciones entre estratos, objetos y restos o elementos constructivos forman, de hecho, un solo contexto..

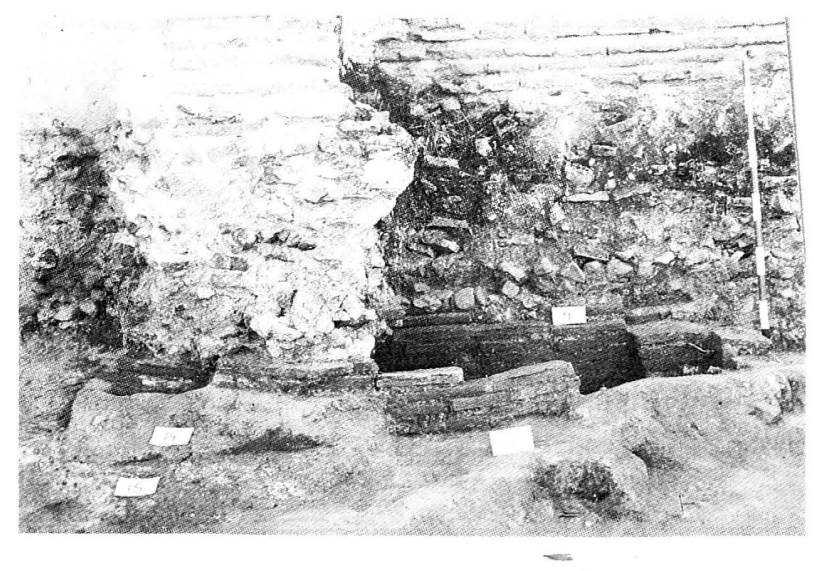

Fig.10.- El contrafuerte cedió por estar cimentado sobre una sepultura anterior. Parroquial de Erustes (Toledo). 1986. 


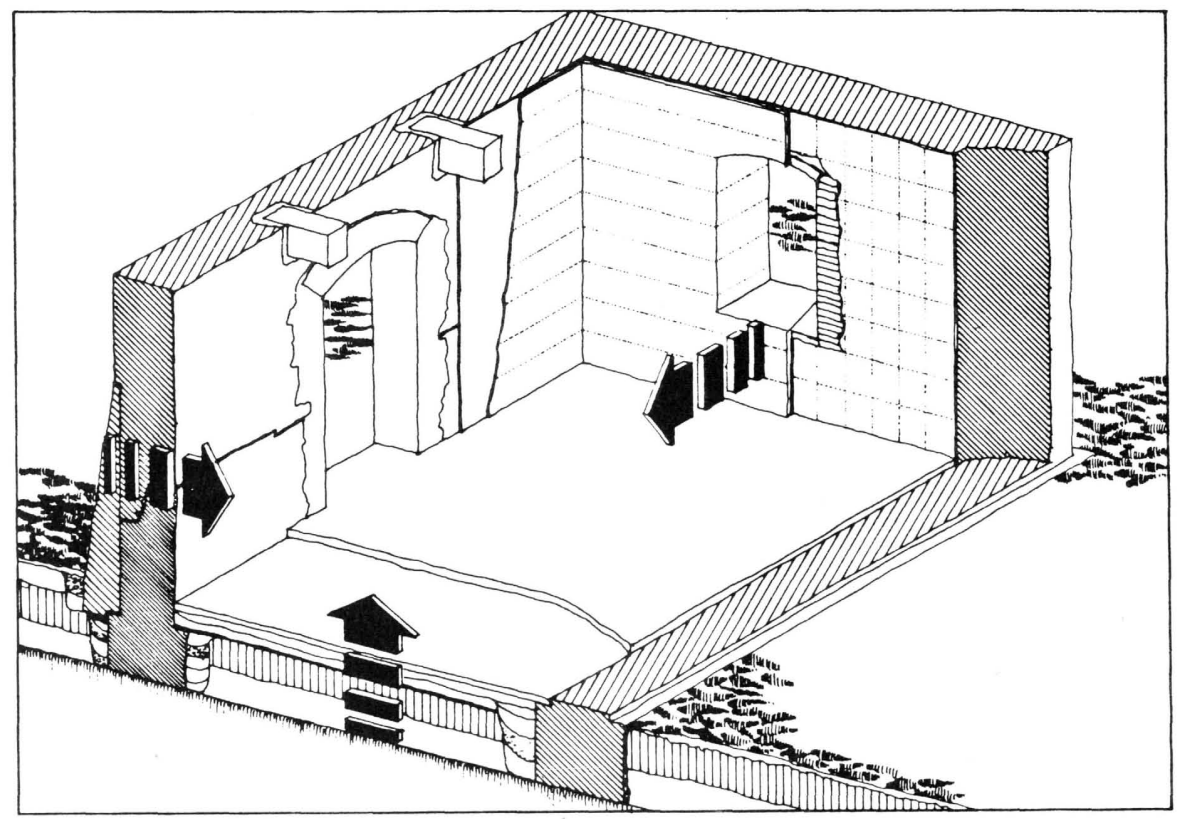

Fig.11.- Estratos y elementos constructivos forman, de hecho, un solo contexto. Planos de estratificación de un edificio, según Parenti, 1988.

\section{6.- Investigación arqueológica y restauración arquitectónica.}

restauradores y arqueólogos son, de hecho, únicos testigos de supresiones, de anulaciones y modificaciones definitivas: a ellos y sólo a ellos, les es confiada la libertad de tomar decisiones relativas a la supervivencia de partes de construcciones, o, en su caso, de sedimentaciones históricas, y de documentar lo que suprimen. R. Francovich.

Como hemos definido, no existe una relación directa entre la importancia formal o artística de los materiales que forman parte de un edificio histórico y las relaciones estratigráficas de antero-posterioridad que se producen en su estructura. Estas "relaciones", que no son simplemente materiales, pueden desaparecer con las más simples labores de conservación y a la inversa, conservarse después de una restauración durísima.

Hemos de tener en cuenta que estas relaciones se producen en el encuentro entre las distintas partes de la estructura del edificio, en las juntas, y éstas son perceptibles únicamente en la superficie del edificio, por lo que este problema es, en primera instancia, preferentemente epitelial. Las teorias conservacionistas han permitido importantísimas y durísimas intervenciones estructurales que han transformado el sistema estructural y constructivo del edificio siempre que la superficie visible del monumento permaneciese inalterada, pues se tenía el convencimiento de que era la superficie del material con toda su carga histórica la que se debía conservar.

(c) Consejo Superior de Investigaciones Científicas

Licencia Creative Commons 3.0 España (by-nc)
S. Pérez Arroyo comenta al referirse a la restauración del Monasterio de Carracedo: Es fácil recordar cómo una ruina informa sobre si misma dejando al descubierto distintos estratos... El restaurador conoce la tendencia a la destrucción que anida en todo proceso constructivo... La habilidad de toda buena intervención en estos términos estaría en saber aproximarse a la obra sin destruir estas pieles o estas superficies de contacto que guardan tanto de la historia última del edificio.

Limpiezas y rejuntados de paramentos, zunchados y recrecidos en las cabezas de los muros, encapotados de bóvedas, sustituciones, repeticiones e invenciones de elementos constructivos -sillerías, cornisas, decoraciones, etc.-, son típicas actuaciones restauradoras que, a la vez que son más o menos irreversibles en su construcción, provocan inevitablemente la pérdida de datos necesarios para el conocimiento histórico de la construcción del edificio que se restaura; los morteros antiguos, las secuencias de superposición y demolición en los muros, su forma de construcción, los materiales y su textura superficial, los encuentros de los distintos elementos constructivos - muros con bóvedas, huecos en los muros, etc.- pueden desaparecer con las más o menos sencillas obras de consolidación antes descritas.

Por este motivo, y salvando las diferencias metodológicas y las diferencias que existen en la finalidad del trabajo, se puede decir que son equiparables la restauración de un edificio y la excavación arqueológica de un yacimiento: así como durante una excavación se destruye información 


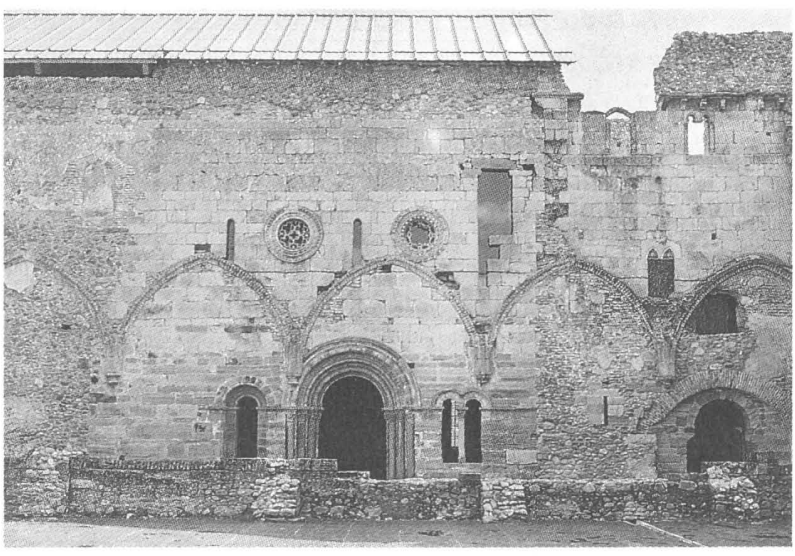

Fig.12.- Aproximarse a la obra sin destruir las superficies de contacto que guardan tanto de la historia última del edificio. Restauración del monasterio de Carracedo ( León). Pérez Arroyo, 1991.

histórica mientras ésta misma se obtiene, durante la obra de restauración se pierden huellas de la cultura constructiva en que se sitúa el edificio, a la vez que se construye la nueva solución.

El convencimiento de que con la obra de restauración estamos destruyendo o transformando elementos con contenido histórico, es el que nos permite establecer paralelismo entre la manipulación que del edificio histórico se efectúa durante la obra de restauración con el proceso de una excavación arqueológica y, por tanto, nos exige en ésta la utilización y realización de mecanismos similares de documentación, registro y control.

¿Por qué es importante introducir y establecer paralelismo entre el proceso de una obra con el de una excavación? Existen dos poderosas razones: la primera, porque, de no hacerlo así, destruiríamos documentación histórica (estratigráfica) inherente al propio edificio. La segunda, porque este análisis del edificio es extraordinariamente importante para su comprensión, aportando datos fundamentales para la restauración del mismo, como son la identificación de los elementos que componen cada fase del mismo, la reconstrucción e hipótesis de la forma que tuvoel edificioen cada momento de su historiay, finalmente, la explicación de los motivos y causas que han propiciado cada una de las transformaciones que se han producido.

Por este motivo pensamos que durante el proceso de una obra de restauración se debería, dentro de lo posible, seguir el proceso metodológico de una "excavación" arqueológica y contar en todo momento con una documentación estricta de aquello sobre lo que se interviene y especialmente de aquello que se destruye. Cualquier obra de restauración que no tenga en cuenta este punto de vista, puede ser tan destructiva de la documentación histórica que conserva la estructuraarquitectónica, comopuede serlo una excavación ilegal en un subsuelo arqueológico.
Desde este punto de vista restaurar debe implicar en primera instancia reconocer -documentar- todos estos elementos y sus relaciones, no necesariamente para conservarlos ni para ponerlos de nuevo en uso, sino primordialmente para comprender, a través de ellos, la vida del edificioy, en su caso, a posteriori, salvaguardarlos y transmitirlos con conocimiento de causa. Esta actividad tiene que ser minuciosamente escrupulosa con todos los elementos y sus relaciones, para no perder valores; totalmente independiente de la decisión de conservar o desechar cada uno de ellos, para no estar mediatizaday, por lo tanto, previa a la intervención propiamente dicha. Es esta independencia y anterioridad en la lectura la que garantiza la objetividad del conocimiento y la del proyecto de intervención.

En este sentido restaurar se convierte en documentar, pero superando la idea tradicional de que "excavar es documentar". Esta expresión en la excavación suele entenderse como que se documenta para no perder definitivamente los contextos y las relaciones que hemos ido destruyendo. Nosotros estamos dándole otro sentido, documentamos para "leer el documento construido", para reconocer todos sus valoresy, a partir de ese reconocimiento, tener la posibilidad de restaurarlos. Es el proceso de descubrimiento que está en la base de la restauración según la teoría clásica de Brandi.

\section{7.- Importancia del método estratigráfico en el debate sobre la restauración.-}

El dilema planteado al inicio de este escrito, entre recuperar y restaurar la forma primitiva del edificio que ha llegado hasta nosotros o conservarlo en su estado actual como documento, sigue vigente en la actualidad. En este sentido J. Rivera plantea que, formuladas las grandes teorías de la restauración durante el siglo XIX y principios del siglo XX, ha sido imposible plantear nuevas vías: Grave es el problema de la bipolaridad de las tendencias de la restauración, por un lado la histórica, por otro la estética (ya planteadas por Brandi y además eje de toda la problemática de la restauración moderna).

A pesar del tiempo transcurrido, la sensación de que el valor documental del edificio histórico existe, pero que no se puede concretar materialmente, ni definir, ni describir, y es intangibley específico de cada edificio, es una constante de las posiciones conservacionistas y es moneda, todavía común, en las discusiones sobre los criterios de restauración. Pedro Navascués, en sus críticas justificadas a las intervenciones que han olvidado los aspectos históricos en su actuación, afirma: ...Afortunadamente hayquienes, por el contrario, manifiestan un sincero respeto por aquello que singulariza una determinada arquitectura, esto es, su condición histórica, impresa en los materiales, disposición formal, usos, carácter y concepción global del edificio, 


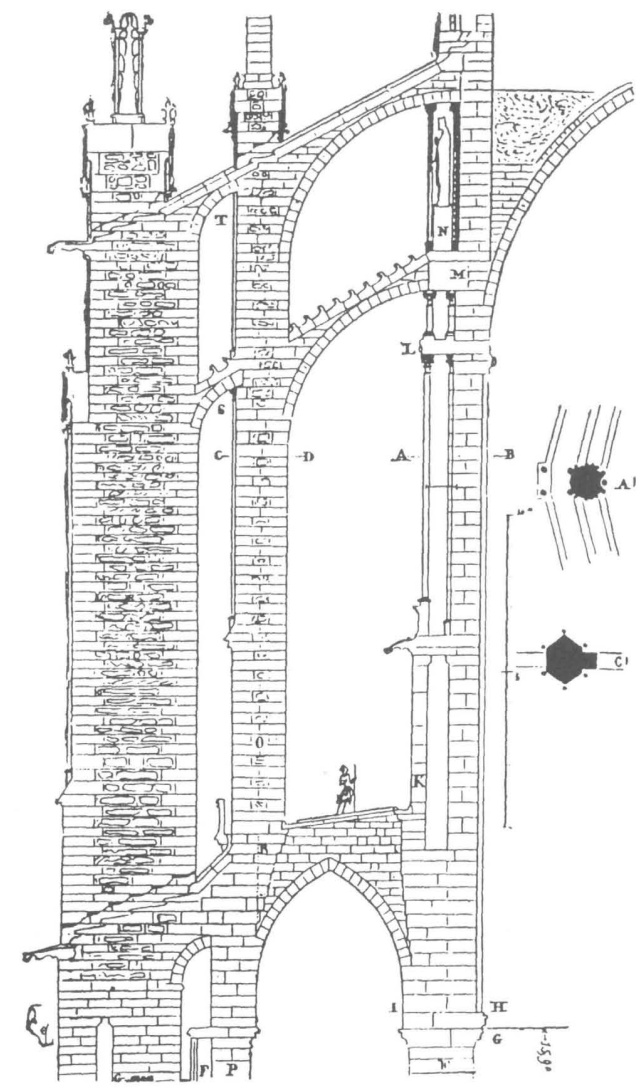

Fig.13.- Viollet se acerca a la restauración desde un análisis históricoconstructivo profundo de la arquitectura gótica. Análisis de la hipótesis de la ruina de la catedral de Beauvois.

sometiendo el proyecto a esta realidad, tan real como intangible, pero que perdida la cual, aquel viejo edificio deja de tener interés como testigo de la historia para convertirse en mero contenedor..

El dislate hallegado a tales extremos que la discusión se ha centrado en algún momento en determinar si es más bella la forma del edificio arruinado y transformado por el paso del tiempo o si la belleza se encuentra en la recuperación de la forma originaria del edificio como valor "auténtico" de la arquitectura. A este respecto es importante recordar el debate sostenido en las Jornadas sobre Restauración realizadas por el Ministerio de Cultura en 1987, parte del cual transcribo:

A.González. A mi la ruina me produce una profunda tristeza, la respeto por supuesto, pero conmover, a mí la ruina no me conmueve en absoluto, como me imagino que a un médico no le conmueve nada un enfermo, como no sean aquellos médicos paternalistas que acaban poniéndole un duro debajo de la almohada al enfermo. Yo, si le puedo dar el antibiótico, no le voy a dar ningún duro, y si no encuentro sistema para curarle, buscaré alguno. No me conmueve nada la ruina; es un problema de mentalidad... llegará un día que a través de la tecnología podamos conservarlo todo. No sé si tiene mucho interés conservarlo todo. Para mí, no.

S. Pérez-Arroyo. A mi el misterio, que es lo que leo en la ruina, me gusta. También ese misterio, en realidad lo que significa es desconocimiento, impotencia de una sociedad para interpretar determinados códigos lingüisticos excesivamente alejados en el tiempo.

Por otro lado, la frustración y crispación que produce la certeza de que cualquiera que sea la restauración que se efectúe sobre el edificio histórico le hace perder de forma inexorable su valor como documento, sigue estando en el centro de la polémica y parece que, a pesar de los años, las palabras de los autores citados siguen vigentes en la actualidad y las teorías de restauración repiten, sin aportar posibilidades nuevas, el mismo problema. En este sentido se manifiesta recientemente J. Ramos, sobre la pérdida de estos valores documentales, después de la dura restauración de San Miguel de la Escalada, y exige que no se toque el interior de Santiago de Peñalba: La tremenda dificultad de acceso han propiciado la extraordinaria conservación de todo lo que en ella supone un mayor valor histórico, arqueológico y antropológico... Es un monumento vestido, al que nada sobra y que de nada carece. No es el interior habitual de una iglesia restaurada...

Frente a esta valoración acientífica, basada en una intuición no demostrada y en valoraciones puramente románticas, desde el campo de la historia de la arquitectura se han desarrollado estudios históricos centrados en los aspectos mas concretos de la misma, relacionando forma, construcción, estructura y evolución con la de los estilos artísticos y con la de los conocimientos científicos de su momento. Estos estudios dotaron a los arquitectos de una herramienta "objetiva" con la que enfrentarse con garantías de éxitoa las soluciones de recuperación formal y estilistica $\mathrm{y}$, sobre todo, de una metodología científica para acometer los problemas constructivos y estructurales que presentaba laarquitectura histórica. Desde estas posturas, se ha criticado con dureza, no falta de razón, las posturas conservacionistas que reclamaban, como una fatalidad del destino, la muerte y desaparición de la ruina.

La importancia de Viollet se centra, precisamente, en que su aproximación a la restauración se realiza desde un análisis histórico-constructivo profundo de la arquitectura gótica, aunque en sus realizaciones se obviaran el conocimiento y la recuperación de otros valores documentales. Sin embargo, la generalización de los principios de Viollet, provocó durante el siglo XIX, que sus innumerables seguidores, sin el método, ni los conocimientos constructivos y, por supuesto, sin la valía del arquitectofrancés, construyeran innumerables "fantasías neogóticas" sobre los grandes monumentos medievales, con la única justificación (proclamada por Viollet) de devolverlos a un estado ideal que podían no haber tenido 


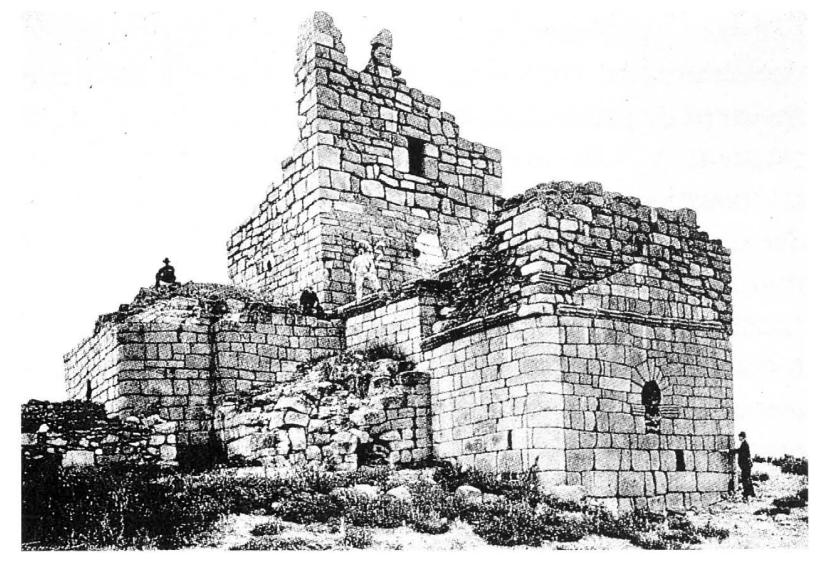

$a$

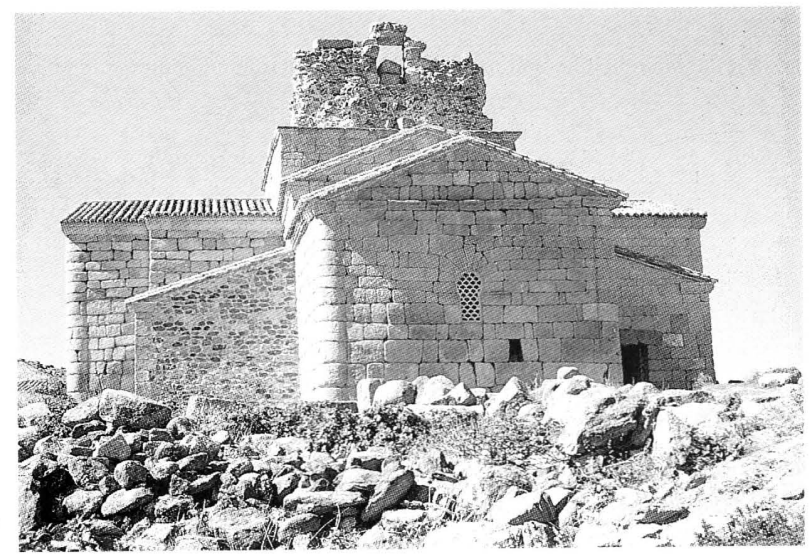

$c$
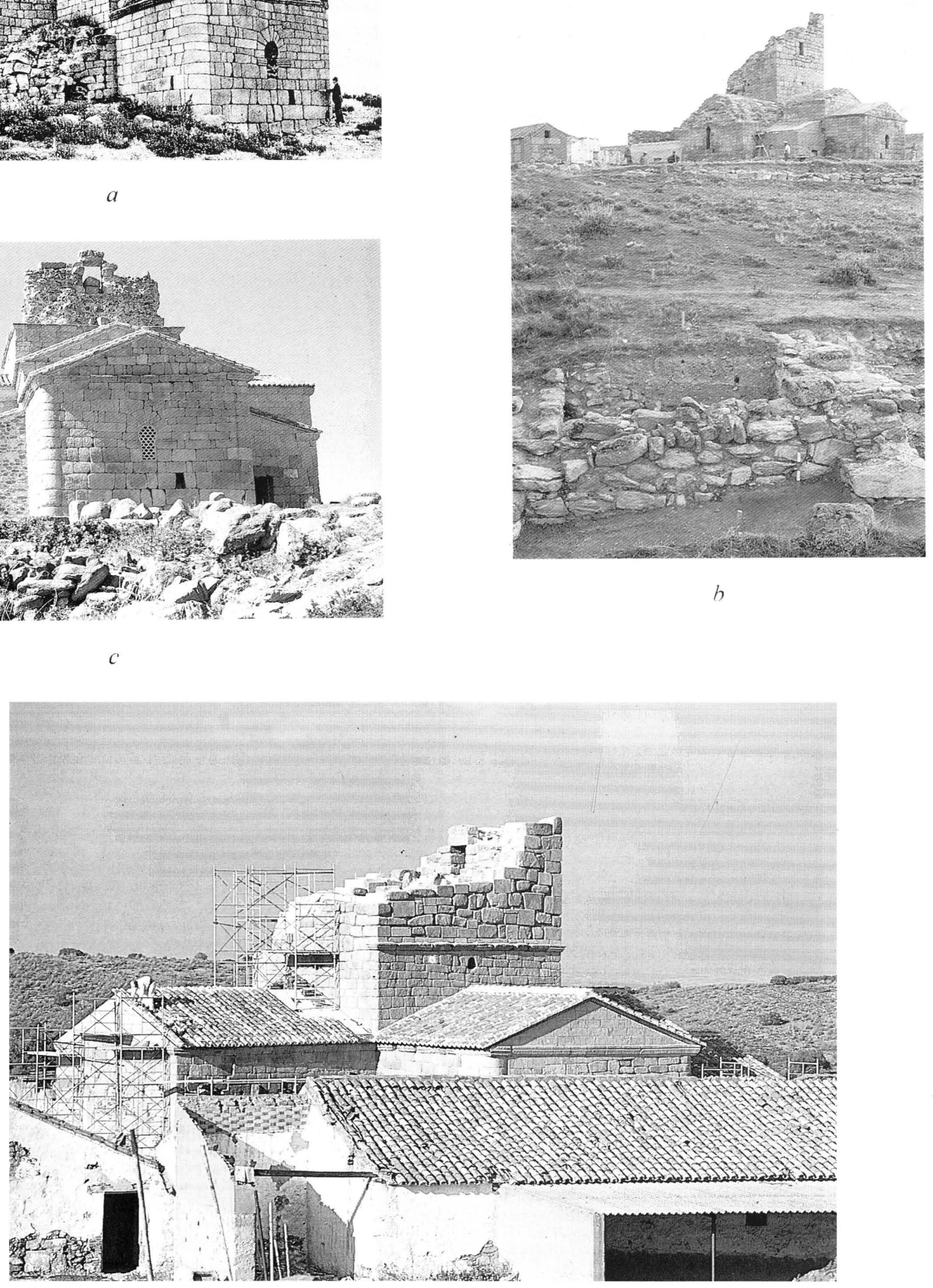

$d$

Fig.14.- a) Santa María de Melque (Toledo). Con los restos de fortificaciones medievales, según Gómez Moreno,1911. b) Relación con los contextos arqueológicos, 1971. c) Tras desmontar la torre medieval en 1972 con la intención de recuperar la volumetría primitiva del cimborrio. d) Restauración de la torre en 1994.

(c) Consejo Superior de Investigaciones Científicas Licencia Creative Commons 3.0 España (by-nc)

http://informesdelaconstruccion.revistas.csic.es 
nunca. Estos autores, en su afán por conseguir una tipología ideal para el edificio que estaban restaurando, abusaron en sus intervenciones de subjetivismo, consecuencia de una banalización del análisis histórico del edifício.

El desastre en la intervención sobre los monumentos se ha producido siempre cuando el arquitecto ha obviado el valor histórico y los valores documentales inherentes al propio edificio y ha antepuesto de un modo completamente subjetivo y arrogante, sus diseños de "estilo" -tanto de carácter "neo" como moderno- a los valores de la arquitectura sobre la que intervenía. Con esta óptica, podemos establecer un paralelismo entre las actuaciones decimonónicas contra las que luchó Torres Balbás, con multitud de proyectos realizados en los últimos años con técnicas y "diseño" actual. Es evidente que estas intervenciones cuando han partidode un análisis superficial del edificio preexistente han fracasado. En este sentido se manifiesta L. de Grassot en su análisis sobre los acontecimientos de los últimos años de la restauración monumental en España. Porque el caos no se produjo como pretenden algunos tratadistas-por lapropia actividad creativa, válida en sí misma, sino porque demasiado a menudoibaacompañadadel olvidode ese valor documental

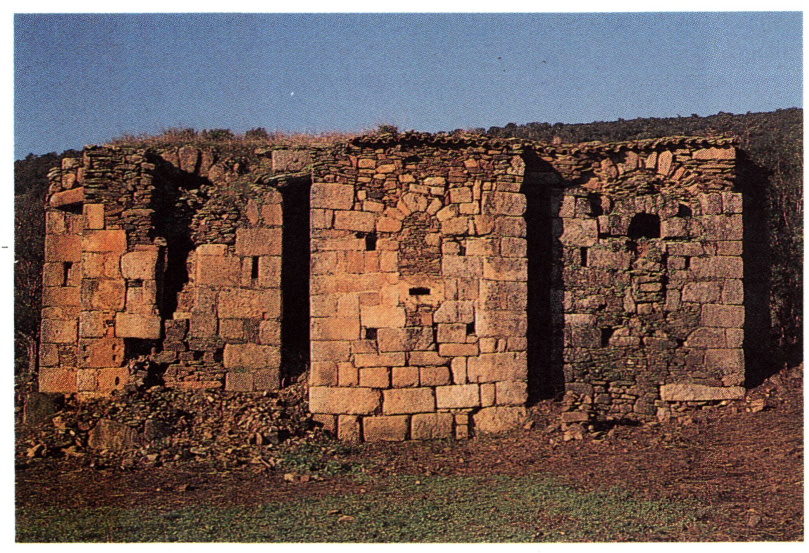

$a$

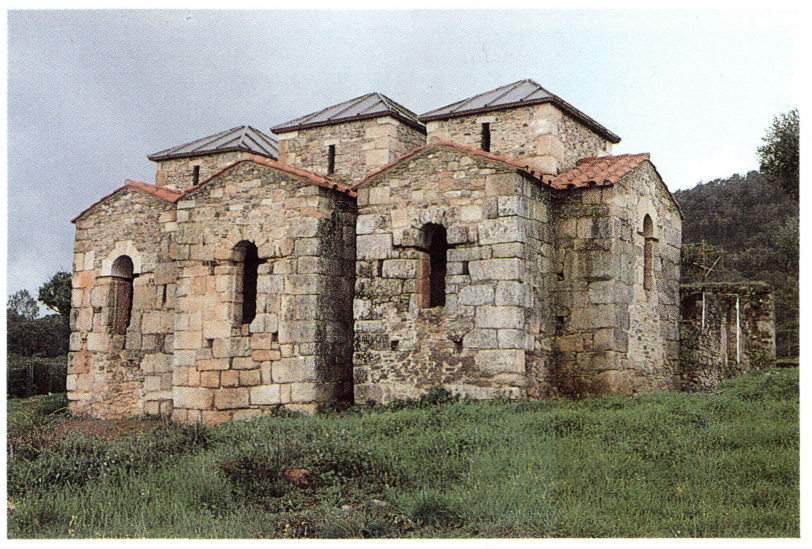

$b$

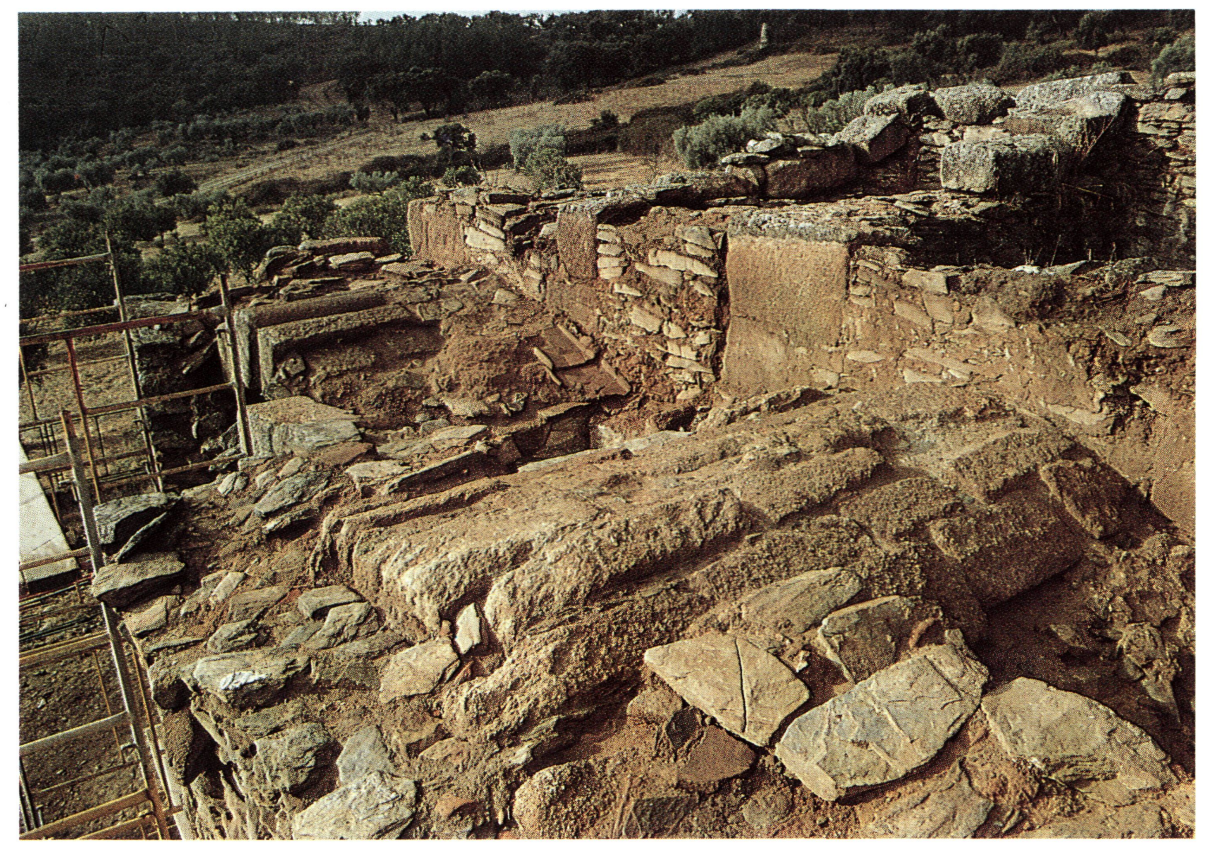

Fig.15.- a) Santa Lucía del Trampal (Cáceres). Cabecera y cimborrios antes de restaurarla, 1984. b) Tras su restauración, 1991. c) Según los datos aparecidos en la excavación arqueológica de sus cubiertas, 1988.

(c) Consejo Superior de Investigaciones Científicas 
$y$ las actuaciones devenian en destructivas o desnaturalizadoras del monumento.

Además, los estudios históricos que se han realizado acompañando a los proyectos de restauración, no han sido capaces de descender al problema concreto que el edificio planteaba y la restauración exigía. Estos trabajos en la mayoría de los casos se resolvían con la descripción histórico-artística del edificio en sus aspectos formales y estilísticos y, en el mejor de los casos, con la recopilación de archivo de los acontecimientos históricos relacionados con el edificio estudiado. Estas memorias han servido para situar en su contexto histórico el edificio sobre el que se tenía que intervenir, proporcionando al arquitecto únicamente unas pautas con las que fundamentar la intervención. Sólo cuando estas memorias obtenían de los libros de fábrica datos concretos sobre las transformaciones sufridas por el edificio y la memoria histórica abandonaba los aspectos más generales, para centrarse en los aspectos más concretos y específicos del edificio, el trabajo se convertía en una herramienta importante en el proceso de restauración.

La rotura de este enmarañamiento teórico y metodológico que ha rodeado la historia de la restauración ha venido del mundo de la arqueología y, específicamente, del mundo de la arqueología medieval. Ha sido en el desarrollo de estas obras de restauración, donde edificio y yacimiento se presentan formando una unidad histórica y arquitectos y arqueólogos se han vistoobligados a trabajar conjuntamente, donde la polémica histórica se volvió a reproducir de forma virulenta. En estos casos, el mundo arqueológico tampoco fue capaz de ofrecer una respuesta concreta, definiendo en qué consistían los valores documentales que provocaban el efecto evocador del paso del tiempoy se limitó en un primer momento a reconocer el valor arqueológico de la edificación, preconizando un conservacionismo radical y produciendo el enfrentamiento de todos conocido entre arqueólogos y arquitectos
La respuesta al problema planteado ha llegado con el reconocimiento de que el edificio histórico es un elemento estratificado. Este descubrimiento que debemos calificar de muy importante, y el desarrollo de la metodología que permite su aplicación, ha venido de un campo de trabajo pluridisciplinar, que ha exigido a los arqueólogos el conocimiento de las técnicas de proyecto y constructivas de los edificios y a los arquitectos el reconocimiento del carácter estratificado de la edificación.

El reconocimiento de la estratificación del edificio, la aplicación de los principios de la estratificación geológica y el desarrollo de la metodología que permite este análisis ha abierto un nuevo panorama con el que enfrentarse a la restauración de los edificios históricos. En primer lugar, permite distinguir las etapas históricas en las que se construyó el edificio, diferenciando los elementos que pertenecen a cada una de ellas, las relaciones entre los elementos y las actividades constructivas y destructivas que los provocaron. En segundo lugar, la metodologia que permite la realización de estos análisis exige la elaboración de una descripción y una documentación muy precisa y concreta de los elementos constructivos del edificio, proporcionando al arquitecto una herramienta fundamental con la que abordar su restauración. Finalmente, al definir materialmente las relaciones estratigráficas, permite en el proyecto de restauración, por un lado efectuar su consolidación (no se puede consolidar lo que no se conoce), u optar por su eliminación (al haberse realizado previamente su documentación) para recuperar aspectos formales claves del edificio, que pudiesen estar ocultos o transformados por otro elementos menores, y para una mejor comprensión didáctica de su historia.

Por todos estos motivos, el método de análisis estratigráfico se hasituado en el centrode la discusión sobre la restauración monumental, ofreciendo una respuesta análitica y concreta a un problema, que hasta ahora se había planteado en términos formales, estéticos o literarios y convirtiendo en científico lo que fue mera intuición.

\section{BIBLIOGRAFÍA.}

BELLINI, A.; Tecniche della conservazione. Milano, 1990.

BONELLI, R.; Archeologia stratigrafica e storia dell'architettura. Architettura, Storia e documenti, 2, 1986, pp.5-10.

BRANDI, C.; Teoría de la restauración. Madrid, 1992 (Torino, 1977).

CABALLEROZOREDA, L.; La Iglesiay el monasterio visigodo de Sta. María de Melque (Toledo). Arqueología y Arquitectura. Excavaciones Arqueológicas en España, 109, Madrid 1980.
CABALLERO ZOREDA, L.; El método arqueológico para la comprensión del edificio. Dualidad sustrato arqueológicoestructura. Curso de mecánica y tecnología de los edificios antiguos, COAM, Madrid 1987, pp.13-59.

CESCHI, C.; Teoria e storia del restauro. Roma, 1970.

CARANDINI, A., Arqueologia y Cultura material. Editorial Mitre, Textos de antropología. Barcelona, 1.984, (Bari ,1975).

CARANDINI, A.; Archeologia, architettura; storia dell'arte, Archeologia e Restauro dei Monumenti, Firenze, 1988, pp. 31 39. 
FRANCOVICH, R.; Archeologia e restauro: Da contiguitá a unitarietá. Restauro \& Citta, 2, 1985, pp. 14-21.

GONZÁLEZ, A.; Por una metodología de la intervención en el patrimonio arquitectónico. (El monumento como documento y como objeto arquitectónico). "Monumentos y Proyecto", Jomadas sobre Criterios de Intervención en el Patrimonio Arquitectónico, Ministerio de Cultura, Madrid, 1987, pp.37-51.

GONZÁLEZ, A.; Especificidad y dificultad de la restauración de la arquitectura testimonial. Quaderns Científics i Técnics, 4 , Diputació de Barcelona, Barcelona, 1991, pp. 9-15.

GRASSOT, L.; El azaroso paso del rubicón de la restauración monumental en España. Informes de la construcción, 427, Madrid, 1993, pp. 5-17.

HARRIS, E.C.; Principios de estratigrafía arqueólogica. Barcelona, 1991 (Londres, 1979)

LATORRE, P.; El Sitio Histórico de Melque (prov. Toledo). La intervención integrada con una final idad didáctica. Archeologia e Restauro dei Monumenti. Firenze 1988, pp. 157-194.

MIARELLI-MARIANI, G.; Historia de los criterios de intervención en el patrimonio arquitectónico. En "Monumentos y Proyecto", Jornadas sobre Criterios de Intervención en el Patrimonio Arquitectónico, Ministerio deCultura, Madrid, 1988, pp. 14-20.

NAVASCUÉS, P; Presente del pasado. La condición histórica de la arquitectura. Arquitectura Viva, 33, 1993, pp.22-25.

PARENTI, R.; Lalettura stratigrafica delle murature in contest $i$ archeologici e di restauro architettonico. Restauro \& Citta, 2, 1985, pp. 55-68.
PARENTI, R.; La technique di documentazione per una lettura stratigrafica dell 'elevato. Archeologia e Restauro dei Monumenti, Firenze, 1988, pp. 249-279.

PÉREZ ARROYO, S.; La piel y los huesos. Introducción del catálogo de la exposición del proyecto de restauración del Monasterio de Carracedo. Diputación Provincial de León, León, 1987.

RAMOS, J.; La restauración de la arquitectura leonesa anterior al románico. Estado de la cuestión. Quaderns Científics i Técnics, 4, Diputació de Barcelona, Barcelona, 1991, pp. 87-95.

RIEGL, A.; El culto moderno a los monumentos. Madrid, 1987 ( Viena, 1903).

RIVERA, J.; La restauración crítica y la problemática actual. Quaderns Científics i Técnics, 5, Diputació de Barcelona, Barcelona, 1993, pp. 19-27.

RUSKIN, L.; Las siete lámparas de la arquitectura. Barcelona, 1987 (Londres, 1849)

TORRES BALBÁS, L.; La restauración de los monumentos antiguos. Arquitectura, 8, Madrid, 1918, pp. 229-233.

TORRES BALBÁS, L.; A través de la Alhambra, Bol. del Centro Artístico, Granada, 1924, pp. 11-12.

TORRESBALBÁS, L..; Crónica "Entorno ala Alhambra". Obra dispersa, tomo 7 , Madrid, 1983.

VV.AA.; Mesa redonda, 1. ANTÓN CAPITEL, ANTONI GONZÁLEZ, ALFONSO JIMÉNEZ, ESTEVE MACH, SALVADOR P. ARROYO. MODERADOR T. LLORENS. En "Monumentos y Proyecto", Jornadas sobre Criterios de Intervención en el Patrimonio Arquitectónico, Ministerio de Cultura, Madrid, 1988, pp.370-390. 